UDC 338.24

LBC 65.050(2Poc)

\title{
TRANSFORMATION OF ECONOMY IN THE CONDITIONS OF FORMING THE NATIONAL TECHNOLOGICAL INITIATIVE
}

\author{
Elena V. Sibirskaya \\ Plekhanov Russian University of Economics, Moscow, Russian Federation
}

\begin{abstract}
The relevance of the study is conditioned by the need for a clear idea about the upcoming transformation of the Russian economy for implementing the national technology initiative (NTI). Today, Russia is facing a "challenge of development", which determines the necessity of transition to breakthrough scientific and technological development as a major strategic objective for the future, which definitely determines further socio-economic development. In his address to the Federal Assembly of December 4, 2014, Russian President Vladimir Putin outlined the National technology initiative to be one of the priorities of state policy. "On the basis of long-term forecasting it is necessary to understand what challenges Russia will face in 10-15 years, what advanced solutions will be required in order to ensure national security, high quality of life, development of new technological order" (from the message to the Federal Assembly) [6]. The response to this challenge is the National technology initiative, aimed at developing a robust creative and business environment that allows to convert technological breakthroughs to new markets into an element of the system of continuous reproduction of income, human and technological capital. Information base of the research includes legal documents of the Government of the Russian Federation, the official publications under the project office of STI, reports of Russian Academy of Sciences, developments of the Expert Council under the government of the Russian Federation and Agency for strategic initiatives, Federal Agency of scientific organizations, research groups, individual scientists and specialists, Internet resources and the authors' own developments. The first systematic and methodologically coherent statement of the ideology of economy transformation in the conditions of forming national technological initiative is presented in the report "Framework of the National technology initiative" of Scientific and organizational administration of RAS. The author deals with the problem of economy transformation aimed at transition to STI. The solution of this problem is impossible without carrying out a specific state policy. As a result, it is emphasized that over the past years this situation, which has been exacerbated by external conditions, objectively requires the development of new approaches to socio-economic and technological development of the country and abandoning failed models. It is obvious that the problem solution makes it necessary, firstly, to provide technological independence of the country, to get free from technology "needle" by means of import substitution. Secondly, it requires the transformation of the economy in order to create qualitatively new types of products based on the latest achievements of science. Thus, in the short term (5-7 years) the main problems of import substitution must be solved, and in the long term (20-30 years) - it is necessary to make the transition to advanced technological structure and transformation based on national technology initiative.
\end{abstract}

The present research was funded by the Plekhanov Russian University of Economics. activity.

Key words: transformation, technological structure, national technology initiative, economic policy, innovation

УДК 338.24

ББК $65.050(2 \mathrm{Poc})$

\section{₹ ТРАНСФОРМАЦИЯ ЭКОНОМИКИ В УСЛОВИЯХ ФОРМИРОВАНИЯ НАЦИОНАЛЬНОЙ ТЕХНОЛОГИЧЕСКОЙ ИНИЦИАТИВЫ}

\section{Елена Викторовна Сибирская}

Российский экономический университет им. Г.В. Плеханова, г. Москва, Российская Федерация

Аннотация. Актуальность исследования обусловливается необходимостью четкого представления о предстоящей трансформации в российской экономике для реализации национальной технологической инициативы 
(НТИ). Сегодня Россия стоит перед лицом «вызова развития», который определяет необходимость перехода к прорывному научно-технологическому развитию как важнейшей стратегической задаче на перспективу, безусловно определяющей дальнейшее социально-экономическое развитие. В Послании Федеральному собранию 4 декабря 2014 г. Президент России Владимир Путин обозначил Национальную технологическую инициативу одним из приоритетов государственной политики. «На основе долгосрочного прогнозирования необходимо понять, с какими задачами Россия столкнется через 10-15 лет, какие передовые решения потребуются для того, чтобы обеспечить национальную безопасность, качество жизни людей, развитие отраслей нового технологического уклада» [6]. Ответом на этот вызов является Национальная технологическая инициатива, нацеленная на формирование развитой творческой и бизнес-среды, позволяющей превратить технологические прорывы на новые рынки в элемент системы непрерывного воспроизводства доходов, человеческого и научнотехнологического капитала. Информационной базой исследования стали нормативно-правовые документы Правительства РФ, официальные публикации в рамках проектного офиса НТИ, доклады РАН, разработки Экспертного Совета при Правительстве Российской Федерации и Агентства стратегических инициатив, Федерального агентства научных организаций, научных коллективов, отдельных ученых и специалистов, ресурсы сети Интернет и собственные разработки автора. Первое системное и методически целостное изложение идеологии трансформации экономики в условиях формирования национальной технологической инициативы представлено в докладе «Основы Национальной технологической инициативы» Научно-организационного управления РАН. В ходе исследования рассмотрены задачи трансформации экономики с целью перехода на НТИ, решение которых невозможно без проведения определенной государственной политики. В итоге подчеркивается то, что сложившаяся в последние годы ситуация, усугубленная внешними условиями, объективно требует выработки новых подходов к социально-экономическому и технологическому развитию страны и отказа от не оправдавших себя моделей. Очевидно, что для решения проблемы необходимо, во-первых, обеспечить технологическую независимость страны, освободиться от технологической «иглы», что решается в рамках импортозамещения. Во-вторых, требуется трансформация экономики с целью создания качественно новых видов продукции на основе последних достижений науки. Таким образом, в краткосрочной перспективе (5-7 лет) должны быть решены основные проблемы импортозамещения, а в долгосрочной (20-30 лет) - необходимо осуществить переход к перспективному технологическому укладу и трансформации с учетом национальной технологической инициативы.

Данное исследование выполнено при финансовой поддержки Российского экономического университета имени Г.В. Плеханова.

Ключевые слова: трансформация, технологический уклад, национальная технологическая инициатива, экономическая политика, инновационная активность.

\section{Актуальность трансформации эконо- мики в контексте представлений о наци- ональной технологической инициативе.} Трансформация экономических систем - пожалуй, наиболее трудная проблема реформационной практики. Ее решение требует реализации ряда сложнейших задач: преодоления кризисного спада и выхода на режим устойчивого и эффективного роста; демилитаризации и глубокого обновления структуры производства, реконструкции его материально-технической базы и применяемых технологий; органичного и равноправного включения национальной экономики в мирохозяйственные связи. Стратегическая цель - подготовка предпосылок для перехода от современной индустриальной стадии хозяйства к постиндустриальной, информационной его стадии [7].

Трансформация экономических систем призвана сформировать предпосылки экономи- ческого роста и глубокой перестройки структуры хозяйства в соответствии с общественными потребностями, современными техникотехнологическими возможностями, с требованиями экономической эффективности и экологически безопасного устойчивого развития, стратегически ориентированного на достижение нового технологического уклада.

Прорыв к новому укладу - единственный выход из сложившейся ситуации. В противном случае России грозит потеря технологического суверенитета, деиндустриализация и утрата технологических достижений. Поэтому ключевым направлением экономической политики должно стать осуществление трансформации промышленности на основе национальной технологической инициативы. Национальная технологическая инициатива (НТИ) - долгосрочная комплексная программа по созданию условий для обеспече- 
ния лидерства российских компаний на новых высокотехнологичных рынках, которые будут определять структуру мировой экономики в ближайшие 15-20 лет [5].

Предпосылки будущей трансформации российской экономики. Разумеется, становление нового технологического уклада, как и развитие его ключевого фактора - национальной технологической инициативы, происходит не на пустом месте. Предпосылки для этого создавались в ходе предшествующего периода инновационного развития.

Для того чтобы оценить основные тенденции в развитии инновационной составляющей в экономике страны в целом, рассмотрим данные Росстата о деятельности инновационных предприятий в целом по России (табл. 1).

Как видно из данных таблицы 1, в 2015 г. удельный вес российских предприятий, осуществляющих технологические, организационные, маркетинговые инновации, в общем чис- ле организаций снизился на $6,1 \%$ и составил 9,3 \% по сравнению с 9,9 \% в 2014 г., что говорит о замедлении развития инновационного сектора экономики страны, которое наблюдается с 2012 года [2]. Информация о динамике инновационной активности организаций наглядно представлена на рисунке 1.

Как видно из данных рисунка 1, в 20102015 гг. наблюдается нисходящий тренд в динамике инновационной активности организаций в России, начиная с 2012 г. происходит ежегодное снижение удельного веса организаций, осуществляющих инновационные разработки, в общем количестве организаций РФ.

Несмотря на снижение удельного веса организаций, осуществлявших инновации, в период с 2012 до 2014 г. сохранялись тенденции роста отгруженных инновационных товаров, выполненных работ, оказанных услуг. В то же время с 2012 г. темпы роста объема инновационных товаров, работ, услуг замедлились, в

Таблица 1

\section{Основные показатели инновационной деятельности в РФ по данным Росстата в 2010-2015 гг.}

\begin{tabular}{|l|c|c|c|c|c|c|}
\hline \multicolumn{1}{|c|}{ Показатели } & 2010 & 2011 & 2012 & 2013 & 2014 & 2015 \\
\hline $\begin{array}{l}\text { Инновационная активность организаций, в \% (удельный } \\
\text { вес организаций, осуществлявших инновации, в общем } \\
\text { числе обследованных организаций) }\end{array}$ & 9,5 & 10,4 & 10,3 & 10,1 & 9,9 & 9,3 \\
\hline $\begin{array}{l}\text { Темп роста инновационной активности организаций, } \\
\text { в \% к прошлому году }\end{array}$ & - & 109,5 & 99,0 & 98,1 & 98,0 & 93,9 \\
\hline $\begin{array}{l}\text { Отгружено товаров собственного производства, выпол- } \\
\text { нено работ и услуг собственными силами, млрд руб. }\end{array}$ & 25795 & 33407 & 35944 & 38335 & 41233 & 45525 \\
\hline $\begin{array}{l}\text { Удельный вес инновационных товаров, работ, услуг в } \\
\text { общем объеме, в \% }\end{array}$ & 4,8 & 6,3 & 8,0 & 9,2 & 8,7 & 8,4 \\
\hline $\begin{array}{l}\text { Стоимость отгруженных инновационных товаров, вы- } \\
\text { полненных работ, оказанных услуг, млрд руб. }\end{array}$ & 1238 & 2105 & 2876 & 3527 & 3587 & 3824 \\
\hline $\begin{array}{l}\text { Темп роста объема отгруженных инновационных това- } \\
\text { ров, выполненных работ, оказанных услуг, в \% к про- } \\
\text { шлому году }\end{array}$ & - & 170,0 & 136,6 & 122,6 & 101,7 & 106,6 \\
\hline
\end{tabular}

Примечание. Составлено и рассчитано по: [9].

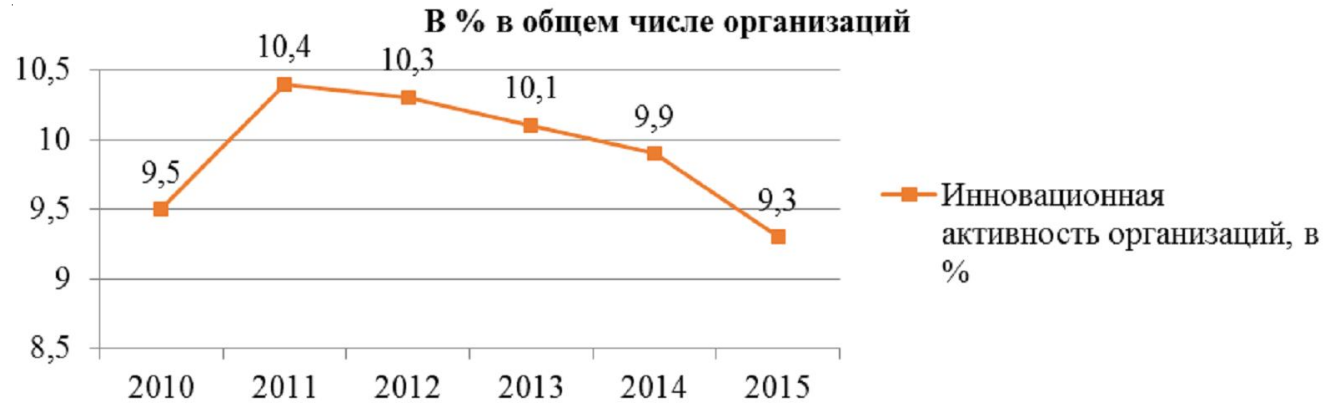

Рис. 1. Динамика инновационной активности организаций в России в 2010-2015 гг.

Примечание. Составлено по: [9]. 


\section{МЕЖДУНАРОДНЫЕ ИНТЕГРАЦИОННЫЕ ПРОЦЕССЫ}

2014 году объем сократился на 1,7 \%, что отчасти было связано со снижением количества организаций РФ, осуществляющих инновационные разработки. В 2015 г. стоимость отгруженных инновационных товаров, выполненных работ, оказанных услуг выросла всего на $6,6 \%$. С учетом уровня инфляции за 2015 г. в размере $12,9 \%$ можно говорить о снижении реального объема отгруженных инновационных товаров, выполненных работ, оказанных услуг. Наглядно информация о динамике стоимости отгруженных инновационных товаров, выполненных работ, оказанных услуг представлена на рисунке 2.

Как видно из данных рисунка 2, в динамике стоимости отгруженных инновационных товаров, выполненных работ, оказанных услуг в РФ наблюдается восходящий тренд. Предварительный анализ тренда с использованием модели линейной регрессии показал, что ежегодно стоимость отгруженных инновационных товаров, выполненных работ, ока- занных услуг в РФ увеличивается в среднем на 515,11 млрд рублей.

Информация об объеме ассигнований бюджетных средств, направляемых на поддержку исследований и разработок, за 20102015 гг. [2] представлена в таблице 2.

Как показал анализ данных в части инновационного развития страны, темпы роста объемов бюджетных средств, направляемых на поддержку исследований и разработок в 2011-2015 гг., снижались, что препятствовало повышению инновационной активности предприятий. В том числе снижался объем бюджетных ассигнований на проведение фундаментальных исследований, в 2012 г. по отношению к прошлому году снижение составило $0,6 \%$, в 2014 г. - 0,5\%, в 2015 г. - 1,2\%. Темпы роста бюджетных ассигнований на проведение прикладных исследований в 2014-2015 гг. были только номинальными и не покрывали даже инфляционную составляющую.

млрд.руб.
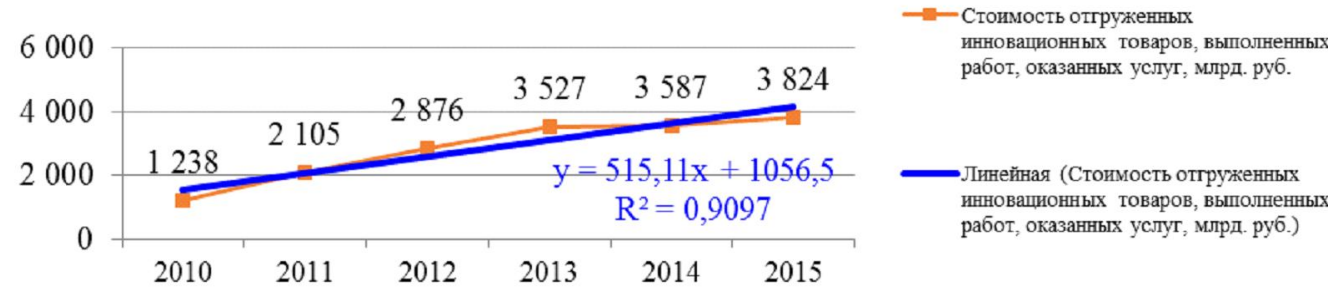

Рис. 2. Динамика стоимости отгруженных инновационных товаров, выполненных работ, оказанных услуг в РФ в 2010-2015 гг.

Примечание. Составлено по: [9].

Таблица 2

Ассигнования на научные исследования из федерального бюджета РФ

\begin{tabular}{|l|c|c|c|c|c|c|}
\hline \multicolumn{1}{|c|}{ Показатели } & 2010 & 2011 & 2012 & 2013 & 2014 & 2015 \\
\hline $\begin{array}{l}\text { Расходы федерального бюджета на научные исследова- } \\
\text { ния, млрд руб. - всего }\end{array}$ & 237,6 & 313,9 & 355,9 & 425,3 & 437,3 & 439,4 \\
\hline $\begin{array}{l}\text { В том числе: } \\
\text { - фундаментальные исследования }\end{array}$ & 82,1 & 91,7 & 86,6 & 122,2 & 121,6 & 120,2 \\
\hline - прикладные исследования & 155,5 & 222,2 & 269,3 & 313,1 & 315,7 & 319,2 \\
\hline $\begin{array}{l}\text { Темп роста расходов федерального бюджета на научные } \\
\text { иследования, в \% к прошлому году }\end{array}$ & - & 132,1 & 113,4 & 119,5 & 102,8 & 100,5 \\
\hline $\begin{array}{l}\text { Темп роста расходов федерального бюджета на фунда- } \\
\text { ментальные исследования, в к прошлому году }\end{array}$ & - & 111,7 & 94,4 & 141,1 & 99,5 & 98,8 \\
\hline $\begin{array}{l}\text { Темп роста расходов федерального бюджета на при- } \\
\text { кладные исследования, в \% п прошлому году }\end{array}$ & - & 142,9 & 121,2 & 116,3 & 100,8 & 101,1 \\
\hline $\begin{array}{l}\text { Расходы федерального бюджета на научные исследова- } \\
\text { ния, в \% от совокупных расходов федерального бюджета }\end{array}$ & 2,35 & 2,87 & 2,76 & 3,19 & 2,95 & 2,81 \\
\hline
\end{tabular}

Примечание. Составлено и рассчитано по: [9]. 
Наглядно данные о динамике объема ассигнований бюджетных средств за 2010-2015 гг., направляемых на поддержку исследований и разработок, представлены на рисунке 3 .

Как видно из данных рисунка 3, в динамике объема бюджетных средств, направляемых на поддержку исследований и разработок в РФ, наблюдается восходящий тренд. Предварительный анализ тренда с использованием модели линейной регрессии показал, что ежегодно бюджетные ассигнования на научные исследования увеличиваются в среднем на 41,389 млрд рублей.

Сопоставим динамику объема бюджетных средств, направляемых на поддержку исследований и разработок в РФ, с динамикой стоимости отгруженных инновационных товаров, выполненных работ, оказанных услуг в РФ, для чего используем простую линейную регрессионную модель. Определим коэффи- циент корреляции, чтобы подтвердить или опровергнуть наличие зависимости стоимости отгруженных инновационных товаров, выполненных работ, оказанных услуг от объема бюджетных средств, направляемых на поддержку исследований и разработок.

Результаты регрессионного анализа представлены на рисунке 4.

Как видно из данных рисунка 4 и выполненных расчетов, между объемом бюджетных средств, направляемых на поддержку исследований и разработок в РФ, и стоимостью отгруженных инновационных товаров, выполненных работ, оказанных услуг существует прямая взаимосвязь, которая может быть достаточно точно описана с помощью модели линейной регрессии (при этом модель показывает, что изменение объема инновационных товаров, работ на 90,97 \% зависит от изменения ассигнований бюджетных средств на под-

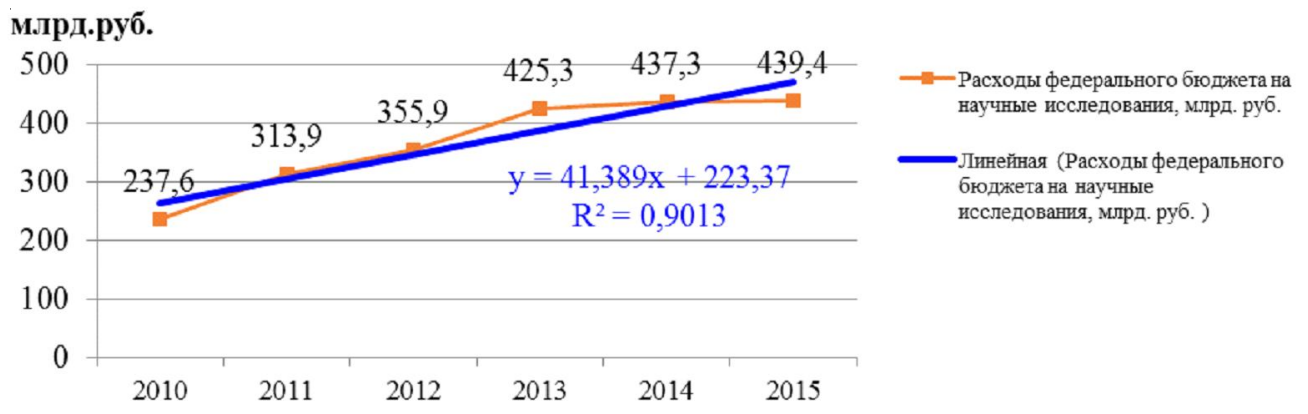

Рис. 3. Динамика объема бюджетных средств, направляемых на поддержку исследований и разработок в РФ, за 2010-2015 гг.

Примечание. Составлено по: [9].

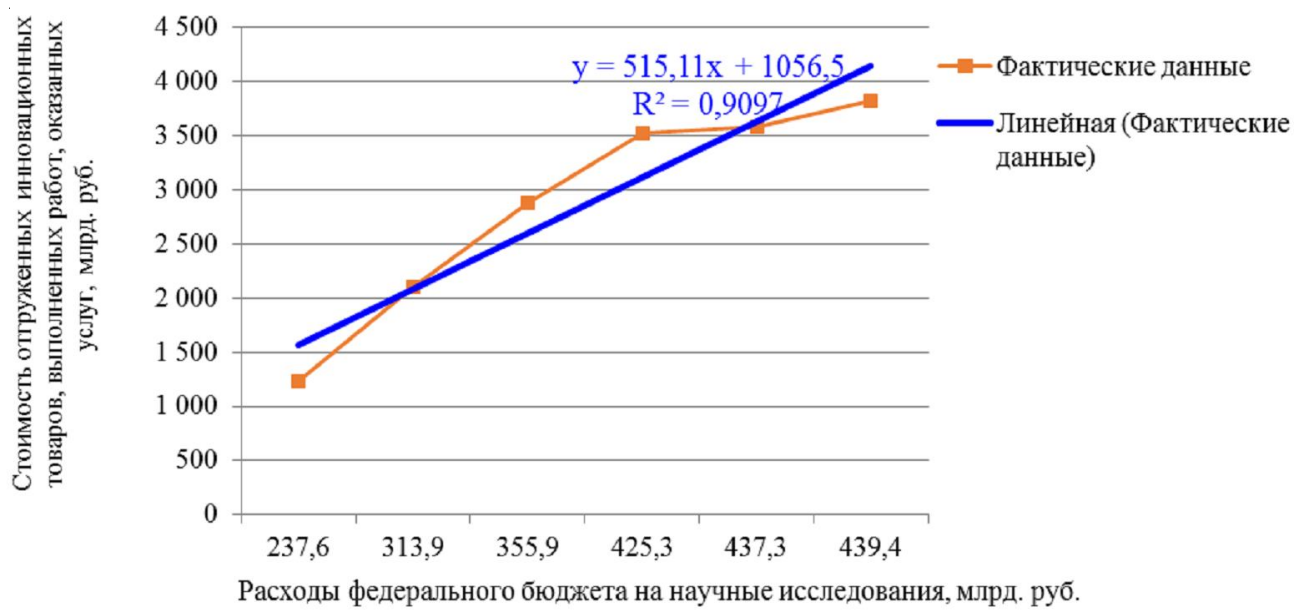

Рис. 4. Оценка взаимосвязи объема инновационных товаров, работ, услуг и объема бюджетных ассигнований на научные разработки

Примечание. Составлено и рассчитано автором по: [9]. 


\section{МЕЖДУНАРОДНЫЕ ИНТЕГРАЦИОННЫЕ ПРОЦЕССЫ}

держку исследований и разработок в РФ). Построение модели линейной регрессии позволяет сделать вывод о том, что при увеличении бюджетных ассигнований на научные исследования на 1 млрд руб., стоимость отгруженных инновационных товаров, выполненных работ, оказанных услуг возрастает в среднем на 515,11 млрд рублей.

Информацию об основных тенденциях и взаимосвязях в развитии инновационной составляющей в экономике РФ следует дополнить данными Росстата о технологических инновациях, в том числе - о технологических инновациях на малых предприятиях, эти данные представлены в таблице 3.

Как видно из данных таблицы 3, в 2015 г. удельный вес российских предприятий, осуществляющих технологические инновации, в общем числе организаций снизился с $8,8 \%$ до $8,3 \%$. Это говорит о том, что технологичес- кие инновации осуществляло меньшее количество предприятий и корпораций, чем это было в 2011-2014 годах. В 2015 г. затраты на технологические инновации сократились на 0,95\% и составили 1200 млрд руб. (в 2014 г. они составляли 1212 млрд руб.), сократились и затраты на технологические инновации у малых предприятий с 9,48 до 12,15 млрд руб., что также характеризует динамику развития инновационного сектора экономики страны как неблагоприятную. Информация о динамике активности организаций в части осуществления технологических инноваций в сопоставлении с ранее приведенными данными об инновационной активности организаций в целом по всем видам инноваций наглядно представлена на рисунке 5.

Как видно из данных рисунка 5, в 20102015 гг. наблюдается нисходящий тренд как в динамике инновационной активности органи-

Технологические инновации в РФ по данным Росстата в 2010-2015 гг.

\begin{tabular}{|l|c|c|c|c|c|c|}
\hline \multicolumn{1}{|c|}{ Показатели } & 2010 & 2011 & 2012 & 2013 & 2014 & 2015 \\
\hline $\begin{array}{l}\text { Удельный вес организаций, осуществляших технологи- } \\
\text { ческие инновации в отчетном году, в общем числе обсле- } \\
\text { дованных организаций, \% }\end{array}$ & 7,9 & 8,9 & 9,1 & 8,9 & 8,8 & 8,3 \\
\hline $\begin{array}{l}\text { Темп роста удельного веса организаций, осуществлявших } \\
\text { технологические инновации, в \% к прошлому году }\end{array}$ & - & 112,7 & 102,2 & 97,8 & 98,9 & 94,3 \\
\hline $\begin{array}{l}\text { Затраты на технологические инновации в фактически } \\
\text { действовавших ценах, млрд руб. }\end{array}$ & 401 & 734 & 905 & 1112 & 1212 & 1200 \\
\hline $\begin{array}{l}\text { Темп роста затрат на технологические инновации, в \% к } \\
\text { прошлому году }\end{array}$ & - & 183,0 & 123,3 & 122,9 & 109,0 & 99,0 \\
\hline $\begin{array}{l}\text { Удельный вес затрат на технологические инновации в } \\
\text { общем объеме отгруженных товаров, выполненных ра- } \\
\text { бот, услуг, \% }\end{array}$ & 1,6 & 2,2 & 2,5 & 2,9 & 2,9 & 2,6 \\
\hline $\begin{array}{l}\text { Затраты на технологические инновации малых предпри- } \\
\text { ятий, млрд руб. }\end{array}$ & - & 9,48 & - & 13,51 & - & 12,15 \\
\hline
\end{tabular}

Примечание. Составлено и рассчитано по: [9].

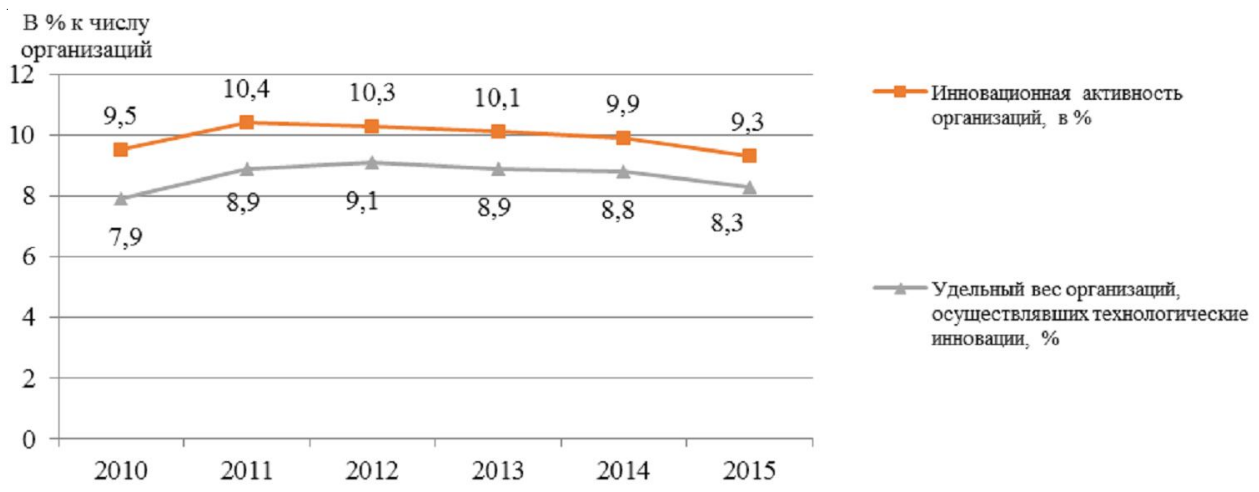

Рис. 5. Динамика удельного веса организаций, осуществлявших технологические инновации, за 2010-2015 гг.

Примечание. Составлено и рассчитано автором по: [9]. 
заций в России, так и в динамике активности организаций в части технологических инноваций, начиная с 2012 г. происходит ежегодное снижение удельного веса организаций, осуществляющих технологические инновации, в общем количестве организаций РФ. В итоге в 2015 г. удельный вес организаций, осуществлявших технологические инновации, составил всего 8,3 \% в общем числе обследованных организаций.

Информация о группах разработанных передовых производственных технологий в целом по РФ представлена в таблице 4.

Как видно из данных таблицы 4, наибольшее количество разрабатываемых передовых технологий в РФ приходится на проектирование и инжиниринг, что связано с высокой потребностью предприятий в высокоэффективных проектно-инженерных решениях. Следует отметить снижение количества разрабатываемых передовых технологий в РФ, которое в 2015 г. наблюдалось по таким группам, как проектирование и инжиниринг, производство, обработка и сборка, аппаратура автоматизированного наблюдения и контроля. В то же время в группе интегрированного управления и контроля, в группе связи и управления, в группе автоматизированной транспортировки, наоборот, произошло увеличение количества разрабатываемых передовых технологий, что связано со смещением потребности именно в этих группах разработок.

\section{Заключение}

В связи с такой ситуацией государство ставит глобальную цель - развитие национальной технологической инициативы, способной обеспечить разработку и производство конкурентоспособной наукоемкой продукции для решения приоритетных задач в области социально-экономического развития и национальной безопасности России.

В течение ближайших 10 лет НТИ должна задать импульс и сформировать основные подходы, ценности, пилотные проекты и истории успеха, с опорой на которые Государство, Общество и Бизнес выстроят систему управления изменениями, обеспечивающую достижение образа будущего к 2035 году [4].

Таблица 4

Динамика и состав разработанных передовых технологий в РФ в 2010-2015 гг., ед.

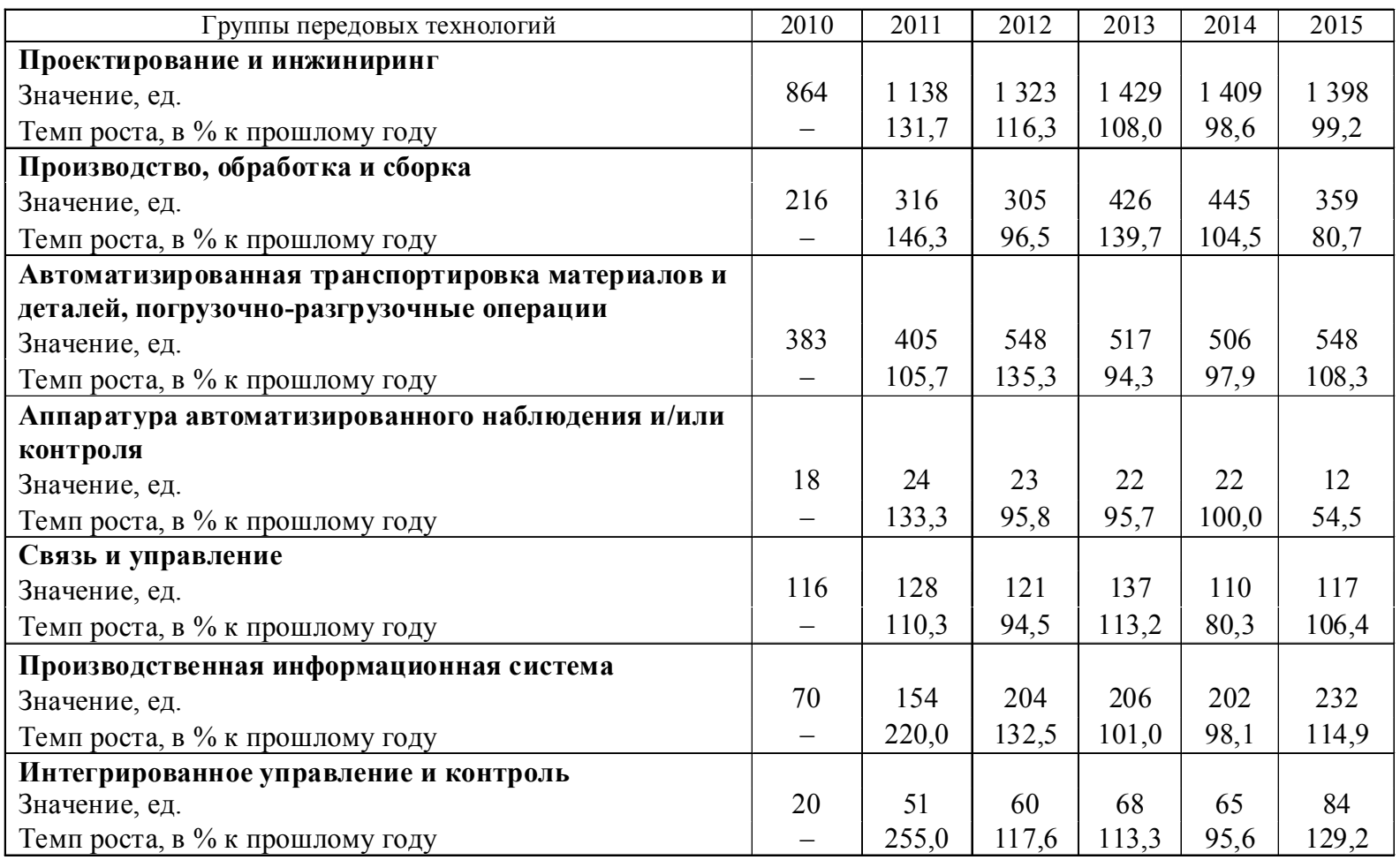

Примечание. Составлено и рассчитано автором по: [9]. 


\section{МЕЖДУНАРОДНЫЕ ИНТЕГРАЦИОННЫЕ ПРОЦЕССЫ}

Разработкой концепции НТИ занимается Правительство России во исполнение поручения Президента РФ. В течение 15-17 лет ожидается существенная трансформация экономики, которая должна осуществляться с учетом потребностей людей и государства, которые изменяются с течением времени, модернизирующейся архитектуры рынков и их трансформации в сетевые ландшафты. В соответствии с заданной целью были поставлены и задачи: разработка промышленных технологий, критически важных для обеспечения разработки и производства конкурентоспособной наукоемкой продукции; технологическое перевооружение отечественной промышленности на основе передовых технологий; создание научно-технологического задела; разработка технологий подготовки и повышения профессионального уровня кадров для высокотехнологичных отраслей промышленности; активизация процессов коммерциализации новых технологий.

Основная сложность трансформации заключается в необходимости одновременного решения как ближне- и среднесрочных, так и долгосрочных задач социально-экономического развития государства и технологических проектов. Проанализировав «Стра- тегию развития России до 2020 года» [7], «Концепцию долгосрочного социально-экономического развития Российской Федерации» [3], отраслевые стратегии и программы, а также Ключевые гипотезы Национальной технологической инициативы [1], мы более детально рассмотрим перечень национальных приоритетов в таблице 5 .

Результаты реализации национальных приоритетов должны быть описаны с точки зрения: осуществления стратегических задач социально-экономического развития; степени парирования выявленных долгосрочных системных вызовов; изменения позиционирования России в мировом научно-технологическом пространстве; изменения уровня конкурентоспособности на внутреннем и внешних рынках, а также эффективности и уровня технологического развития производства; изменения позиционирования России на существующих и перспективных рынках.

\section{СПИСОК ЛИТЕРАТУРЫ}

1. Белоусов, Д. Р. «Образ будущего»: Россия как полюс развития / Д. Р. Белоусов, А. Ю. Апокин, Р. Г. Волков, К. В. Михайленко, Е. А. Пенухина, Е. М. Сабельникова. - Электрон. текстовые дан. - Режим доступа:

Таблица 5

Национальные приоритеты долгосрочного социально-экономического развития Российской Федерации

\begin{tabular}{|c|l|}
\hline № & \multicolumn{1}{|c|}{ Национальные приоритеты } \\
\hline 1 & Оборона и безопасность \\
\hline 2 & Технологическая модернизация образования \\
\hline 3 & Технологическая модернизация здравоохранения, включая медицинскую технику и фармацевтику \\
\hline 4 & Экология и рациональное природопользование \\
\hline 5 & Обеспечение эффективного функционирования и развития нефтегазового комплекса \\
\hline 6 & Энерго- и ресурсосбережение, энергоэффективное потребление \\
\hline 7 & Развитие транспортной инфраструктуры \\
\hline 8 & Технологическая модернизация АПК \\
\hline 9 & Аэронет \\
\hline 10 & Маринет \\
\hline 11 & Автонет \\
\hline 12 & Нейронет \\
\hline 13 & Энерджинет \\
\hline 14 & Фуднет \\
\hline 15 & Хэлснет \\
\hline 16 & Сейфнет \\
\hline 17 & Финнет \\
\hline 18 & Медианет \\
\hline 19 & Персоналнет \\
\hline
\end{tabular}

Примечание. Составлено автором. 
http://www.forecast.ru/_ARCHIVE/Analitics/ForumASI/ NTI_strategy.pdf(дата обращения: 01.16.2017). - Загл. с экрана.

2. Затраты и источники финансирования научных исследований и разработок : Инф.-стат. мат. М. : ФГБНУ НИИ РИНКЦЭ, 2016. -Электрон. текстовые дан. - Режим доступа: http://www.csrs.ru/archive/ stat_2016_finance/finance_2016.pdf (дата обращения: 01.16.2017). - Загл. с экрана.

3. Концепция долгосрочного социальноэкономического развития Российской Федерации на период до 2020 года. - Электрон. текстовые дан. - Режим доступа: http://www.consultant.ru/ document/cons_doc_LAW_82134/ (дата обращения: 01.16.2017). - Загл. с экрана.

4. Национальная технологическая инициатива (НТИ). Программы государственной поддержки. - Электрон. текстовые дан. - Режим доступа: http://fb.ru/article/271054/natsionalnayatehnologicheskaya-initsiativa-nti-programmyigosudarstvennoy-podderjki (дата обращения: 01.16.2017). - Загл. с экрана.

5. Национальная технологическая инициатива. Электрон. текстовые дан. - Режим доступа: http:// www.nti2035.ru/nti/(дата обращения: 01.16.2017). -Загл. с экрана.

6. Послание Президента Федеральному собранию (04.12.2014). - Электрон. текстовые дан. - Режим доступа: http:/www.kremlin.ru/events/president/ news/47173. - Загл. с экрана.

7. Сибирская, Е. В. Стратегия развития региональных промышленно-производственных комплексов на основе интеграции экономических процессов : автореф. дис. ... д-ра экон. наук / Сибирская Елена Викторовна ; Воронеж. гос. техн. ун-т. - Воронеж : Изд-во ВГТУ, 2004.

8. Стратегии инновационного развития Российской Федерации на период до 2020 года. - Электрон. текстовые дан. - Режим доступа: http://minsvyaz.ru/ common/upload/2227-pril.pdf (дата обращения: 01.16.2017). - Загл. с экрана.

9. Федеральная служба государственной статистики. - Электрон. текстовые дан. - Режим доступа: http://www.gks.ru/wps/wcm/connect/rosstat_main/ rosstat/ru/statistics/science_and_innovations/science/ \# (дата обращения: 01.16.2017). - Загл. с экрана.

\section{REFERENCES}

1. Belousov D.R., Apokin A.Yu., Volkov R.G., Mikhaylenko K.V., Penukhina E.A., Sabelnikova E.M.
"Obraz budushchego»: Rossiya kak polyus razvitiya ["Image of the Future": Russia as a Pole of Development]. URL: http://www. forecast.ru/ ARCHIVE/Analitics/ForumASI/NTI_strategy.pdf. (accessed January 16, 2017).

2. Zatraty $i$ istochniki finansirovaniya nauchnykh issledovaniy i razrabotok: Inf.-stat. mat. [Costs and Sources of Funding for Scientific Research and Development. Information and Statistics Matreials]. Moscow, FGBNU NII RINKTsE Publ., 2016. URL: http://www.csrs.ru/archive/stat_2016 finance/finance_2016.pdf. (accessed January 16, 2017).

3. Kontseptsiya dolgosrochnogo sotsialnoekonomicheskogo razvitiya Rossiyskoy Federatsii na period do 2020 goda [The Concept of Long-Term Socio-Economic Development of the Russian Federation for the Period till 2020]. URL: http://www. consultant.ru/document/cons_doc_LAW_82134/. (accessed January 16, 2017).

4. Natsionalnaya tekhnologicheskaya initsiativa (NTI). Programmy gosudarstvennoy podderzhki [National Technology Initiative (NTI). The Program of State Support]. URL: http://fb.ru/article/271054/ natsionalnaya-tehnologicheskaya-initsiativa-ntiprogrammyi-gosudarstvennoy-podderjki. (accessed January 16, 2017).

5. Natsionalnaya tekhnologicheskaya initsiativa [National Technology Initiative]. URL: http://www. nti2035.ru/nti/. (accessed January 16, 2017).

6. Poslanie Prezidenta Federalnomu sobraniyu (04.12.2014) [President's Message to the Federal Assembly]. URL: http:/www.kremlin.ru/events/ president/news/47173.

7. Sibirskaya E.V. Strategiya razvitiya regionalnykh promyshlenno-proizvodstvennykh kompleksov na osnove integratsii ekonomicheskikh protsessov: avtoref. dis. ... d-ra ekon. nauk [The Strategy of Development of Regional Industrial Complexes Based on the Integration of Economic Processes. Dr. econ. sci. abs. diss.]. Voronezh, VGTU Publ., 2004.

8. Strategii innovatsionnogo razvitiya Rossiyskoy Federatsii na period do 2020 goda [The Strategies of Innovative Development of the Russian Federation for the Period till 2020]. URL: http:// minsvyaz.ru/common/upload/2227-pril.pdf. (accessed January 16, 2017).

9. Federalnaya sluzhba gosudarstvennoy statistiki [Federal State Statistics Service]. URL: http:// www.gks.ru/wps/wcm/connect/rosstat_main/rosstat/. (accessed January 16, 2017). 


\section{МЕЖДУНАРОДНЫЕ ИНТЕГРАЦИОННЫЕ ПРОЦЕССЫ}

\section{Information about the Author}

Elena V. Sibirskaya, Doctor of Sciences (Economics), Professor, Department of Statistics, Plekhanov Russian University of Economics, Stremyanny lane, 36, 117997 Moscow, Russian Federation, Sibirskaya.EV@rea.ru.

\section{Информация об авторе}

Елена Викторовна Сибирская, доктор экономических наук, профессор кафедры статистики, Российский экономический университет им. Г.В. Плеханова, Стремянный переулок, 36, 117997 г. Москва, Российская Федерация, Sibirskaya.EV@rea.ru. 